\title{
POTENCIAL CÍVICO DO CAMPUS: A UNIVERSIDADE FEDERAL DE SANTA CATARINA E A DEMOCRACIA NA CIDADE
}

Potencial cívico del campus: Universidad Federal de Santa Catarina y la democracia en la ciudad The civic potential of the campus: Federal University of Santa Catarina and democracy in the city

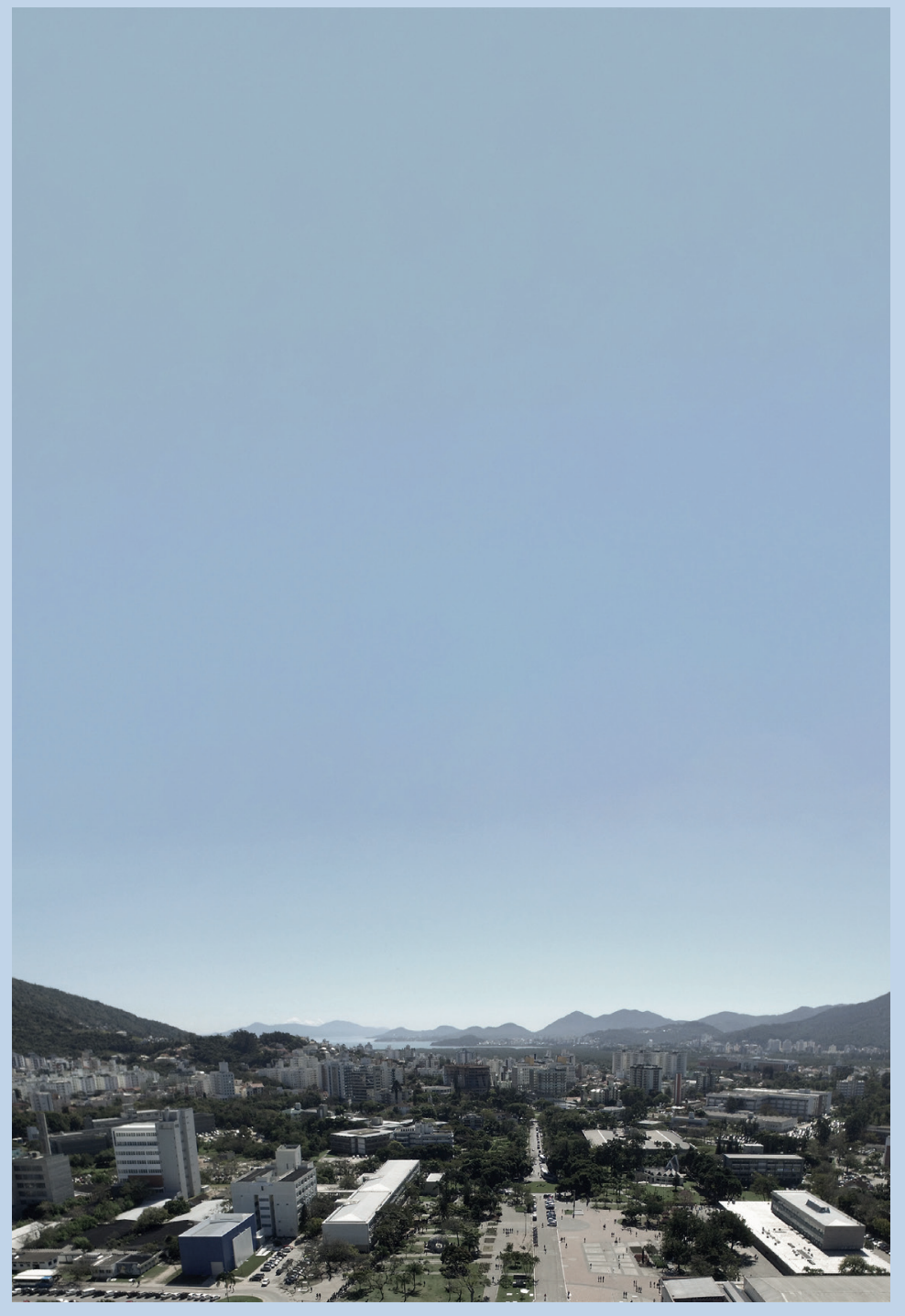

\section{José Ripper Kos}

Professor do Programa de Pós-Graduação em Arquitetura e Urbanismo -. Professor do Programa de Pós-Graduação em Urbanismo. Universidade Federal de Santa Catarina - Universidade Federal do Rio de Janeiro. Florianópolis- Rio de Janeiro. Brasil.

jose.kos@ufsc.br

http://orcid.org/0000-0002-4760-0017

\section{Luis Henrique Pavan}

Mestrando do Programa de Pós-Graduação em Arquitetura e Urbanismo. Universidade Federal de Santa Catarina. Florianópolis, Brasil.

luishpavan@gmail.com

https://orcid.org/0000-0002-1204-2756

\section{Camila Poeta Mangrich}

Mestranda do Programa de Pós-Graduação em Arquitetura e Urbanismo. Universidade Federal de Santa Catarina. Florianópolis, Brasil.

camila.poeta@ufsc.br

https://orcid.org/0000-0002-5817-704X

A praça central do A praça central do Fonte: Autores projeto é parte deConselho Nacional de Desenvolvimento Científico e Tecnológico - CNPq (Processo: 424268/2018-3)

Os autores agradecem ao Conselho Nacional de Desenvolvimento Científico e Tecnológico - CNPq, à Universidade Federal de Santa Catarina - UFSC, ao Laoratório de Segurança em Computação/UFSC (Jean Martina e Fernanda Gomes) e a todos os pesquisadores do Laboratório de Ecologia Urbana/UFSC 


\section{RESUMO}

Este artigo defende o potencial do espaço físico para promover ambientes públicos democráticos. As políticas públicas das universidades nas últimas décadas no Brasil proporcionaram uma mudança expressiva em direção a campi mais inclusivos. Por outro lado, a crescente comoditização urbana reduziu significativamente a diversidade nas áreas públicas da cidade. Este estudo tem como objetivo destacar o papel relevante que o campus universitário pode desempenhar para fornecer áreas cívicas à cidade e avaliar as características espaciais que facilitam os encontros democráticos. Em 2019, o campus sede da Universidade Federal de Santa Catarina foi palco de vários eventos para organizar uma resistência contra a redução do orçamento federal da educação. $O$ estudo parte do reconhecimento das regiões universitárias que acolhem estudantes de áreas de estudo mais diversas. Posteriormente, assembleias da comunidade universitária no campus foram registradas e seus atributos espaciais analisados. Espaços mais flexíveis e permeáveis no térreo dos edifícios influenciaram essas escolhas para reunir e confrontar ideias. Essas descobertas apontam para soluções opostas à prática atual, voltadas para entradas mais protegidas. Além disso, os resultados sugerem orientações para a universidade reduzir suas barreiras, convidando a cidade a suas áreas abertas através de edifícios que oferecem serviços gratuitos aos seus cidadãos.

Palavras Chave: Espaço público, campus universitário, cidadania, infraestrutura social, democracia

\section{RESUMEN}

Este artículo defiende el potencial espacial para promover entornos públicos democráticos. Las políticas de las universidades públicas en las últimas décadas en Brasil han proporcionado un cambio expresivo hacia campus más inclusivos. Por otro lado, la creciente mercantilización urbana ha reducido significativamente la diversidad dentro de las áreas públicas de la ciudad. Este estudio tiene como objetivo resaltar el papel relevante que puede desempeñar el campus universitario para proporcionar áreas cívicas a la ciudad y evaluar las características espaciales que facilitan los encuentros democráticos. En 2019, el campus principal de la Universidad Federal de Santa Catarina fue el escenario de varios eventos para organizar una resistencia contra la reducción gubernamental del presupuesto educativo. El estudio parte del reconocimiento de las regiones universitarias que albergan estudiantes de áreas de estudio más diversas. Posteriormente, se han registrado asambleas de la comunidad universitaria dentro de esta región y se han analizado sus atributos espaciales. Los espacios más flexibles y permeables en la planta baja de los edificios influyeron en estas elecciones para reunir y confrontar ideas. Estos descubrimientos apuntan a soluciones opuestas a la práctica actual, orientadas hacia entradas más protegidas. Además, sugieren direcciones para que la universidad reduzca sus fronteras invitando a la ciudad a sus áreas abiertas a través de edificios que ofrecen servicios gratuitos a los ciudadanos de la ciudad.

Palabras Clave: Espacio público, ciudad universitaria, nacionalidad, infraestructura social, democracia

\section{ABSTRACT}

This article advocates the potential space for promoting public democratic environments. In recent decades, public university policies in Brazil have provided an expressive shift towards more inclusive campuses. On the other hand, the growing urban commercialization has significantly reduced diversity within the city's public areas. This study aims to highlight the relevant role that university campuses can play in providing civic areas for the city and to evaluate the spatial characteristics that facilitate democratic gatherings. In 2019, the Federal University of Santa Catarina's main campus was the stage of several events to protest against the government's reduction of the education budget. The study starts from the recognition of the university areas that house students from more diverse areas of study. Subsequently, university community assemblies have been registered within this area and their spatial attributes have been analyzed. More flexible and permeable spaces on the buildings' ground floor influenced these choices to gather and confront ideas. These findings point to solutions that go against current practices, aimed towards more protected entrances. Furthermore, they suggest directions so the university reduces its boundaries, inviting the city into its open areas through buildings that offer free services to its citizens.

Keywords: Public space, university campuses, citizenship, social infrastructure, democracy 


\section{INTRODUÇÃO}

AS / Vol. 38. No58 / AGOSTO 2020 // ISSN impresa 071 6-2677 / ISSN digital 0719-6466

POTENCIAL CÍVICO DO CAMPUS: A UNIVERSIDADE FEDERAL DE SANTA CATARINA E A DEMOCRACIA NA CIDADE

José Ripper Kos, Luis Henrique Pavan y Camila Poeta Mangrich
Implantado em 1960, o campus sede da Universidade Federal de Santa Catarina (UFSC) é um dos poucos espaços públicos sobreviventes à pressão da comercialização e exploração turística de Florianópolis. E é a partir do território da UFSC e seus 40.000 estudantes, que buscamos alinhavar o potencial democrático da universidade pública na promoção da cidadania brasileira, confirmando Dober (1992) de que o design do campus é uma arte cívica que ressoa com significado para a geração atual.

A relevância das universidades frente a posturas antidemocráticas é conhecida no país. Os movimentos estudantis sempre tiveram destaque e se ampararam nas dependências físicas das universidades para a organização de seus movimentos. Acreditamos que considerar o território acadêmico como estrutura à parte das cidades não colabora para uma adequada caracterização da universidade como infraestrutura social e como espaço cívico. Ofertando serviços à comunidade e promovendo a diversidade de encontros, a inserção do campus no contexto urbano materializa funções que extrapolam sua função primária.Trabalhamos ainda no sentido de explicitar a priorização cívica na construção de cidades que correspondam mais às necessidades sociais do que aos imperativos de lucro do sistema capitalista.

Ao final da segunda década do século XXl, contrariando opiniões de que os protestos atuais se limitam a publicações nas redes sociais, o ano de 2019 veio restaurar o papel do espaço público como palco da democracia contemporânea. As manifestações públicas, que ilustram páginas dos livros de história brasileira, ganharam novos registros de ocupação das ruas e praças em movimentos que, embora organizados pela internet, seguiram inspirados pelas gerações passadas, unindo suas vozes em defesa dos direitos por elas conquistados.

A complexidade dos fatos sequenciados neste capítulo da história brasileira faz com que seja uma tarefa longínqua entender e teorizar esse período adequadamente. Dentro deste recorte temporal, o presente artigo parte de um trabalho de reexame do papel democrático de um campus universitário na trama urbana. Trata-se de reafirmar a relevância do campus frente aos cenários cada vez mais voláteis e orientados ao acúmulo de capital que se formam nos espaços das cidades. Em cenários onde o potencial cívico das cidades entra, crescentemente, em conflito com processos de comoditização que as acometem (Harvey, 2003; Brenner et al., 2009), a função do campus como infraestrutura social se ressignifica.

Parkinson (2013) defende que a democracia se nutre de tipos específicos de espaços físicos para seu desempenho. A tolerância política é frequentemente associada à convivência entre grupos com posições contraditórias e a diversidade tende a reforçar a percepção da possibilidade de debates plausíveis entre diferentes pontos de vista (Sunstein, 2018). Há arranjos espaciais que amplificam ou silenciam comportamentos que os defensores da democracia consideram valiosos. Buscou-se neste trabalho reconhecer quais as características espaciais e 


\section{CONTEXTO BRASILEIRO}

AS / Vol. 38. No58 / AGOSTO 2020 // ISSN impresa 07 16-2677 / ISSN digital 0719-6466

POTENCIAL CÍVICO DO CAMPUS: A UNIVERSIDADE FEDERAL DE SANTA CATARINA E A DEMOCRACIA NA CIDADE José Ripper Kos, Luis Henrique Pavan y Camila Poeta Mangrich programáticas que diferenciam e alçam um território a um patamar democrático utilizando-se o campus sede da UFSC como laboratório de análise. Como o campus universitário pode ser um território ativo na promoção de cidades mais democráticas? Como esses locais se configuram? Como, de maneira geral, um arranjo espacial de um edifício/ espaço universitário pode amplificar a performance democrática de uma população?

Na contramão do crescimento de 91,6\% da oferta de cursos de graduação no Brasil entre 2003 e 2013 (Brasil, 20l4) e ações afirmativas que floresceram nas universidades, a última década foi marcada por um conjunto de momentos críticos que estremeceu a estrutura dos ideais do ensino público no país. As jornadas de junho, como ficaram conhecidos os protestos que tomaram as ruas em 2013, abriram um cenário de inquietação popular de diversas vertentes ideológicas que culminou numa mudança completa na direção política nacional.

De uma proposta de alteração da Constituição Federal (Brasil, 2016), impondo grande redução dos gastos públicos por 20 anos, à pauta econômica do presidente Jair Bolsonaro, eleito em 20 I 8, investimentos essenciais como ensino e saúde passaram a ser mira do grupo político que assumiu o país. Contra medidas de contenção de recursos destinados às universidades públicas e à produção científica, multidões ocuparam novamente as principais cidades numa série de marchas contrárias ao anunciado retrocesso de conquistas sociais históricas.

Esses movimentos foram amplificados pela capacidade de mobilização nas redes sociais. Os sentimentos expressados na internet são conectados por preocupações reais, de pessoas reais na mesma experiência humana que é demandada nas chamadas online dos eventos (Castells, 2015). Apesar da internet, há de se indagar quais são as características dos locais físicos e grupos de pessoas das manifestações que se iniciam digitalmente, mas que se amparam nos espaços urbanos. A carência de locais públicos para o exercício da cidadania e democracia nas cidades faz com que estes eventos iniciem onde os grupos mais engajados politicamente estão. A ideia de que a democracia depende do espaço físico de várias maneiras contraria a ortodoxia atual na teoria democrática e na ciência política mais ampla, e questões de espaço edificado estão quase inteiramente fora do radar dos estudiosos da política (Parkinson, 2012). Há uma coação nas universidades públicas para que os investimentos sejam reduzidos, ao passo que a demanda pelos serviços públicos ofertados e a pressão por desempenho e produção aumentam. A democracia depende extensamente da disponibilidade de locais públicos, mesmo em uma época tão alegadamente aproximada da internet e da comunicação online. Partindo da interpretação de que os territórios universitários são partes integrantes das cidades, pode-se afirmar que, na situação atual de contingenciamento de recursos, os espaços da performance democrática se encontram em risco. 
Até a primeira metade do século $X X$, as faculdades brasileiras foram edificadas isoladamente e depois elevadas ao patamar de universidade estruturadas sob um corpo mais unitário. Os campi brasileiros, inspirados no tipo estadunidense, têm propensão por espaços de ensino afastados dos centros urbanos, sendo o campus a materialização desse ideal. Segundo Chapman (2006), a história da instituição é contada no campus: onde ele foi implantado, o que foi construído naquele local e o que nele acontece. $\bigcirc$ limite geográfico entre um campus e uma comunidade é uma história edificada de quão separada ou integrada a gestão universitária escolheu ser. No Brasil houve cuidadosa adaptação aos tipos de sociabilidade pretendidas e permitidas dentro das universidades. Afirma Barros (2017) que isso era mais evidente quanto às formas de sociabilidade comum ao campus norte-americano e que era, no entanto, antagônica ao esforço da ditadura brasileira em reprimir manifestações estudantis e docentes, vistas cuidadosamente quando o assunto era a oposição ao regime.

projeto territorial universitário no Brasil encimado pelo governo após o Golpe Militar de 1964 era predominantemente calcado na eficiência econômica, organizacional e de controle sobre os usuários. ○ "Manual sobre o planejamento integral do campus universitário", publicado em 1970 por Rudolph Atcon, um dos assessores norte-americanos mais ativos nos acordos entre o governo brasileiro e americano, é considerado como o principal documento a definir o conjunto de
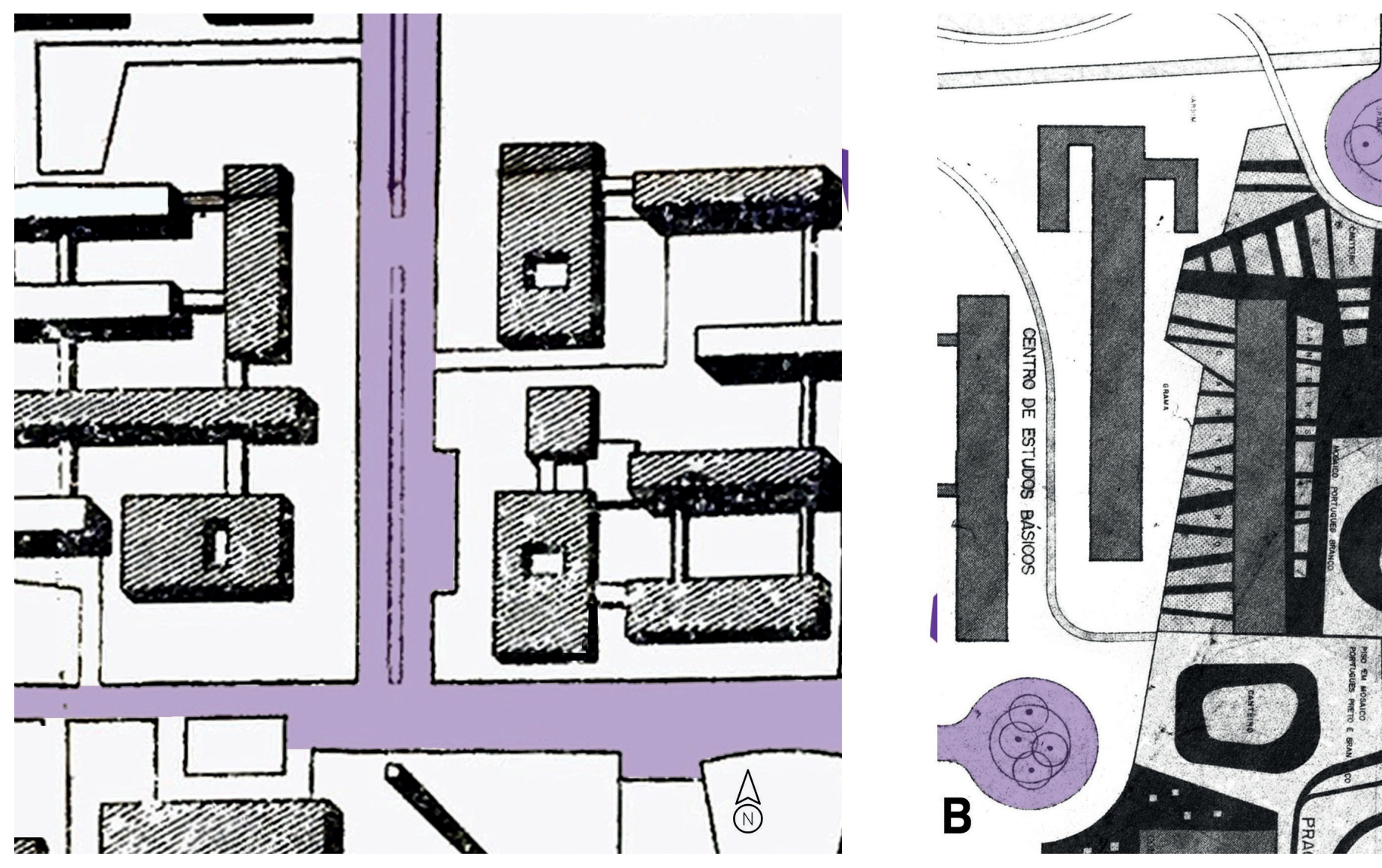
Figura 1

A. Plano de 1957;

B. Projeto de 1970

para Praça da

Cidadania

Campus em 2019.

.

alterado pelos

autores

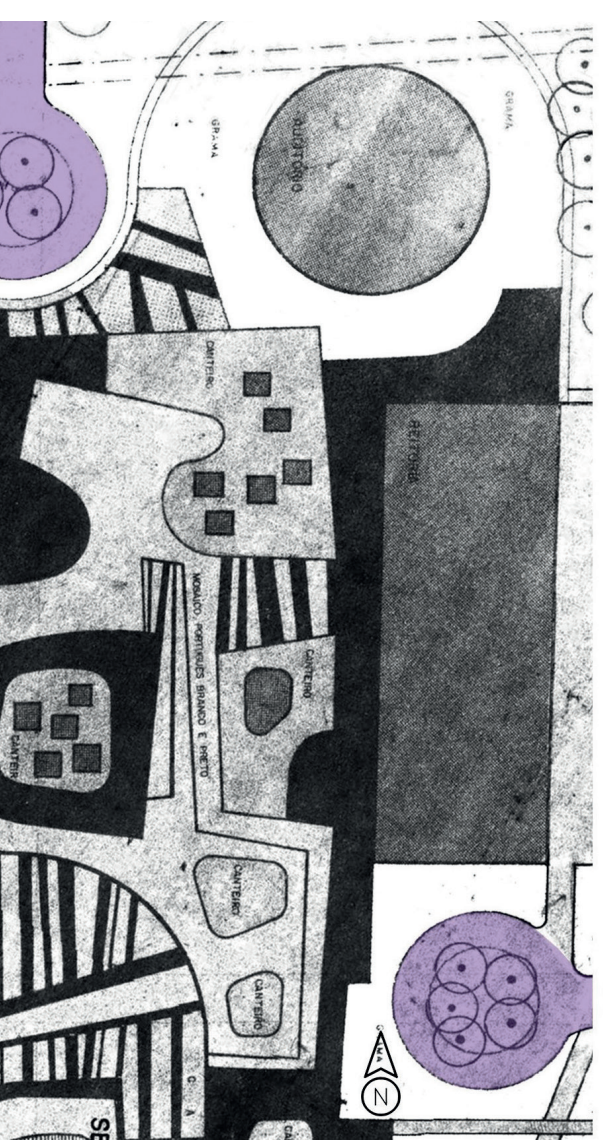

ideias responsável pela caracterização dos campi após a Reforma Universitária de 1968. (Buffa \& Pinto, 2009)

O primeiro Plano Diretor para o campus sede, aprovado em 1957 e parcialmente implantado, foi elaborado pelo arquiteto Hélio Duarte e o engenheiro Ernest Mange (Teixeira, 2009). A conceituação e espacialização geral de setores, o traçado viário e os canais de drenagem foram construídos e permaneceram inalterados, consolidando sua imagem no campus. No ínterim entre 1957 e o segundo plano, de 1964, foram construídos alguns dos edifícios que trataremos adiante, a saber, Centro de Ensino Básico (CCE) de 1957 por Paulo Macedo e Adroaldo Pereira; a sede da Reitoria (1959) Felipe Gama D'Eça e equipe (Teixeira, Yunes, Souza, Sansão \& Godoy, 20 I4). Esses planos e edifícios estão inseridos no contexto de modernização e aprimoramento de técnicas construtivas por que passava a capital catarinense à época, com certa limitação de mão obra técnica local.

Em 60 anos, a estrutura da UFSC avançou segregada da cidade, fortalecendo, contudo, aspectos centrais do campus. A Praça da Cidadania [Figura I] projeto paisagístico de Roberto Burle Marx em 1970 é um marco urbanístico onde ocorre a maior parte dos eventos que resgatam à universidade seu caráter democrático de espaço público. $\bigcirc$ debate que permeia as teorias academicistas e a realidade prática das infraestruturas sociais exige, portanto, uma reavaliação da UFSC como propriedade urbana e o cumprimento legal da sua função social.

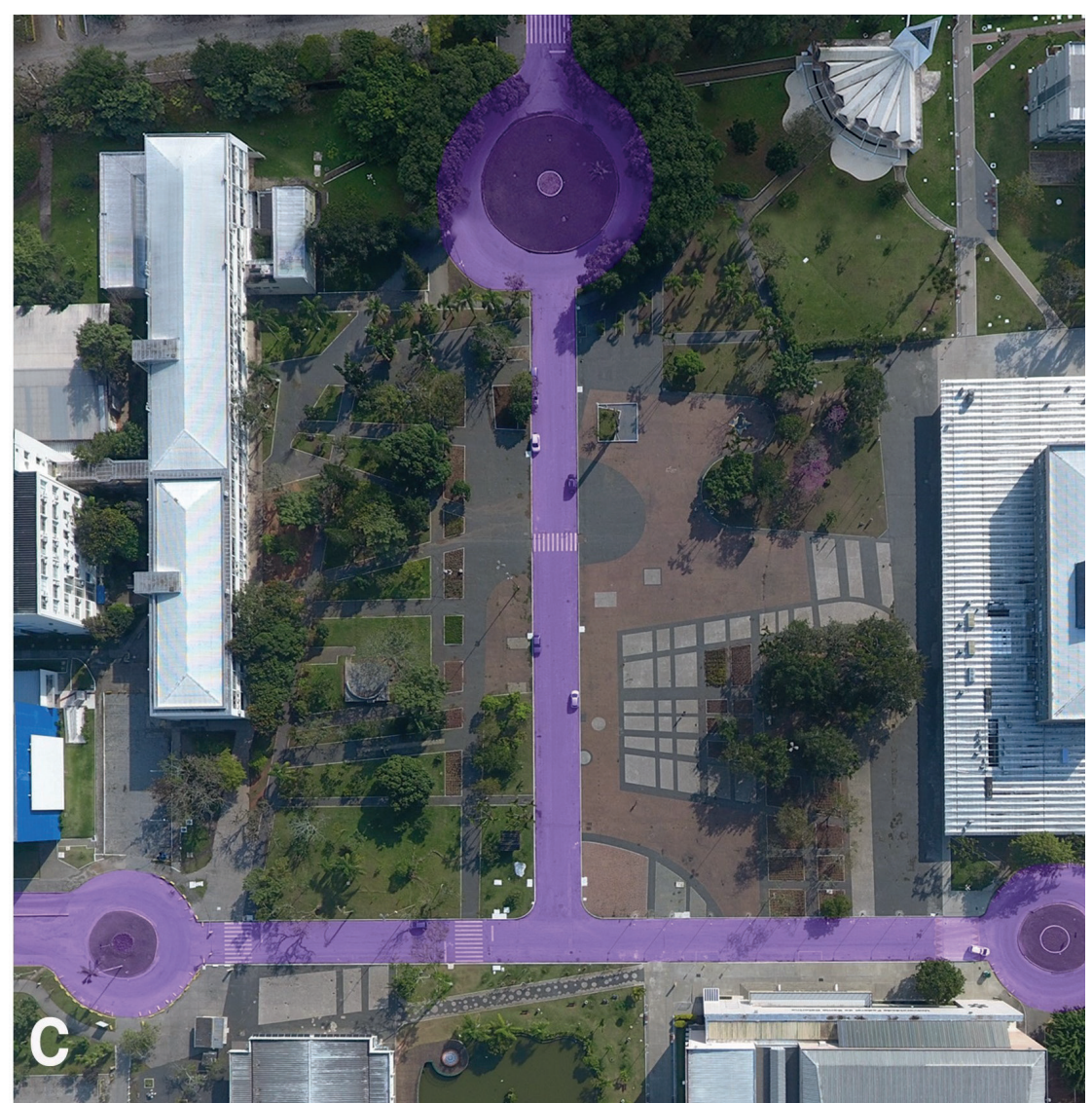




\section{METODOLOGIA}

Figura 2

Inauguración de

la estatua de

Caupolicán en 1939:

Fuente: FOERSTER,

Fuente: FOERSTER,

R. Y MONTECIN

Fonte: 'José Ripper

Kon, Luis Henrique

Pavan, Camila Poeta
O presente artigo foi desenvolvido a partir da exploração de uma análise quantitativa do cotidiano do campus e seu contexto urbano, seguido da avaliação de um recorte temporal realizado a partir da observação qualitativa das manifestações públicas ocorridas ao longo de 2019. Para avaliação das dinâmicas cotidianas do Campus, foi realizado o mapeamento demográfico de pontos de encontro a partir de dados obtidos da conexão dos dispositivos móveis dos alunos de graduação à rede sem fio (Wi-Fi) vinculada ao serviço Eduroam disponível para a comunidade acadêmica internacional. Dados de autenticação, nos quais o usuário pré-cadastrado acessa com segurança a internet foram armazenados nos últimos 10 anos.

Em Mangrich et al (2019) obtivemos significativos indicadores dos efeitos provocados pela divisão funcional e segmentação territorial no campus, permitindo verificar em quais partes havia integração maior entre graduandos de diferentes áreas. Uma menor integração entre alunos de centros de ensino distintos foi verificada nas porções mais periféricas do campus. Nas áreas centrais, consoante aos resultados que apresentaremos posteriormente, foi verificada uma integração mais expressiva. Esses resultados ressaltam a dinâmica fragmentada do campus e reforçam o campus como espaço cívico capaz de potencializar a integração acadêmica e comunitária.

$\mathrm{Na}$ Figura 2, as conexões dos alunos estão representadas agrupadas por centros de ensino, no entorno da Praça da Cidadania. Com os resultados destas dinâmicas cotidianas, buscou-se comprovar através das assembleias de 2019 como o desenho urbano auxilia na promoção do encontro e do papel cívico da universidade.

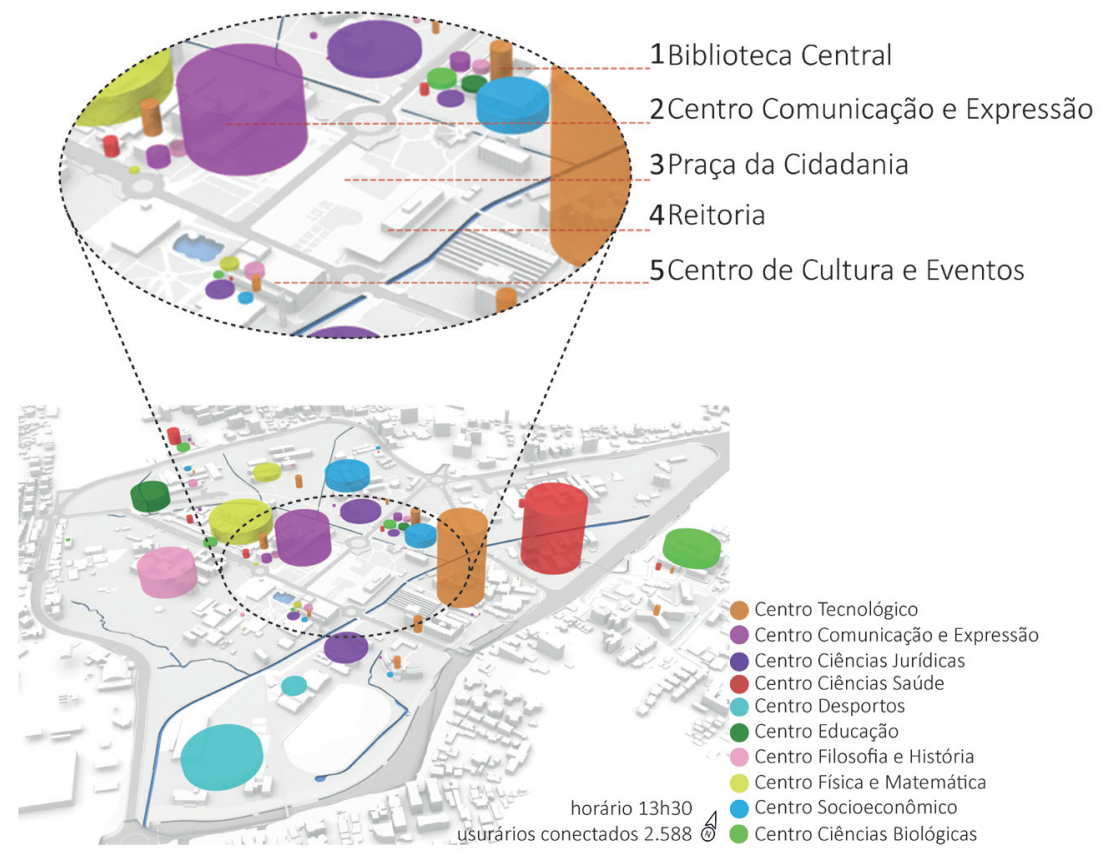




\section{RESULTADOS \\ AS ASSEMBLEIAS NO CAMPUS}

Os locais que abrigam encontros no campus foram analisados com mais detalhe, a partir da consideração feita pelo estudo de Wi-Fi e da relevância da diversidade dos encontros para a promoção de espaços mais democráticos. Desta forma, foram observadas as assembleias mais significativas em termos de público ocorridas na parte central do campus, considerando suas características programáticas e sua espacialidade. A análise das assembleias ocorreu através da observação das dinâmicas das pessoas no território do campus. Foram avaliadas assembleias divulgadas nas redes sociais e páginas oficiais da UFSC na internet, convocando a comunidade ao encontro presencial em defesa da Educação Pública do país.

Além da área central, outros locais foram observados de modo expedito nos demais setores do campus, onde ocorreram eventos no hall interno dos blocos de sala de aula ou ao ar livre. A escolha dos eventos analisados teve como critério a localização geográfica no campus e os grupos de pessoas a eles vinculados.

Posteriormente, na escala da cidade, um transbordamento das inquietações da comunidade acadêmica, materializado em protestos e passeatas nas principais avenidas da macrorregião central de Florianópolis, resultando num breve relato de como o desenho arquitetônico e urbanístico também impacta para além dos limites do campus.

Desta sinergia entre o espaço virtual e o cotidiano do campus universitário, despertou o interesse pelo encontro presencial acadêmico na densificação do debate democrático. Sintonizando o contexto histórico da UFSC com o cenário político que se apresenta na gestão federal vigente em 2019, as linhas que seguem trazem um relato oportunizado por algumas manifestações que ocorreram na universidade no decorrer daquele ano, seja dentro do campus ou, a partir dele, ao longo de toda Florianópolis.

No campus, um destaque intencional foi dado aos eventos ocorridos no entorno da Praça da Cidadania, principal espaço democrático e de integração da UFSC tendo como base um mapa cadastral alicerçado nos térreos das edificações existentes [Figura 3], enumeradas de I a 6. llustradas a partir das observações, as aglomerações de pessoas durante os eventos e as edificações a elas relacionadas estão indicadas em roxo.

- conjunto arquitetônico e paisagístico que compõe a Praça da Cidadania foi planejado para abrigar o caráter cívico da comunidade acadêmica. Ocorre, contudo, que ao longo do desenvolvimento da universidade, escassos foram os recursos financeiros destinados aos seus espaços e, como consequência, a praça acabou perdendo em partes seu potencial de sociabilidade urbana, corroborado pela dominação dos carros estacionados na via que a secciona. 
Figura 3 Indicação das assembleias ocorridas na Praça da Cidadania ( 3 ) e edificações do entorno: Reitoria (4), Centro de cultura e Eventos (5), Centro de Convivência (6) e CCE (2).

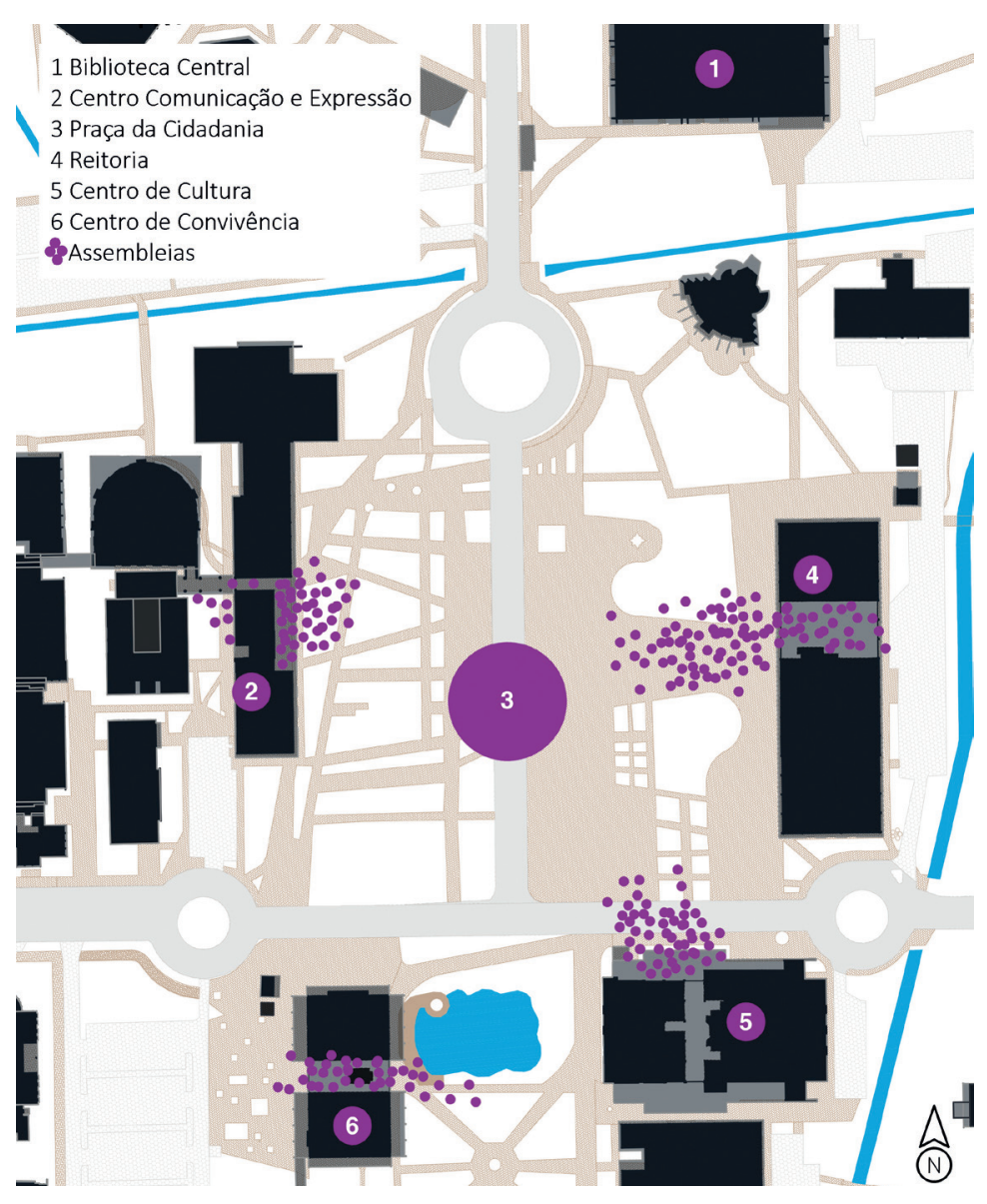

A Figura 4A é um registro da assembleia ocorrida no dia 10 de setembro de 2019, entre os alunos de aproximadamente 70 cursos de graduação, aprovando a Greve Geral dos Estudantes. A magnitude da escala da Praça da Cidadania, sua topografia plana e sua centralidade no campus são fatores que contribuíram para o evento tomasse grande proporção, unindo pessoas oriundas de diversos setores, reassumindo a função originalmente pensada pelo paisagista. Concebidas em períodos distintos da história do campus, a Reitoria em 1959 e o Centro de Cultura e Eventos em 2004, também fazem parte deste cenário e demonstram em suas tipologias prioridades diferentes quanto às oportunidades de encontros.

Até 2004, o auditório da Reitoria [Figura 4B e Figura 4C] era o principal espaço para eventos culturais que reuniam toda a comunidade. As manifestações, ocorridas na Reitoria ao longo de toda a história da universidade, comprovam que sua configuração arquitetônica, alinhada à relação de continuidade e permeabilidade com área externa (Praça de Cidadania) reforçado pela constância do nível térreo do edifício 
Figura 4

Assembleias dos

estudantes ocorridas

na Praça da

Cidadania, 2019.

Fonte: A. Marcelo

Ferro; B-C. UFSC e pelo painel de vidro que delimita o conjunto, oportuniza que estes eventos continuem tendo até hoje esse caráter democrático de livre acesso. Já o Centro de Cultura e Eventos possui um tipo responsável por evidentes barreiras entre o seu principal espaço —o auditório localizado no pavimento superior - e a área externa, limitando os eventos à capacidade predeterminada da grande sala. As áreas de circulação térreas da edificação possuem desnível significativo em relação à praça e uma linearidade que dificulta seu uso como área de encontro, distinguindo abruptamente o caráter semiprivado do interior do espaço público externo.

As reuniões do Conselho Universitário, ocorridas em 2019 neste auditório e abertas à totalidade da comunidade acadêmica, incluindo
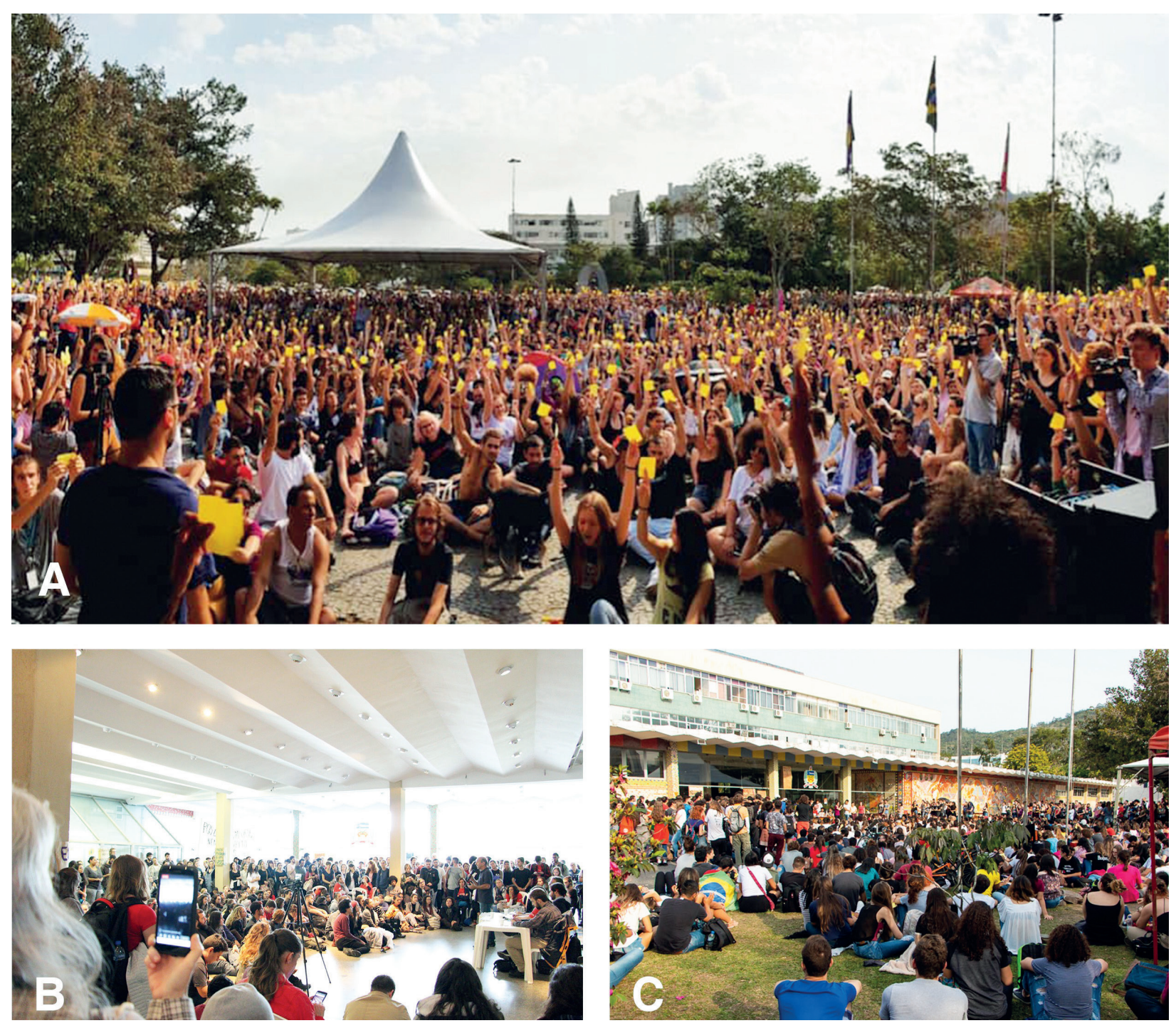
unidades externas ao campus central, ilustraram as restrições de lotação dadas pela configuração do edifício, fato que culminou no fracionamento dos eventos com a ocupação da Praça de Cidadania por parte das pessoas, que assistiram os debates no telão instalado no local, limitando-as a uma participação meramente passiva, de espectador.

Outras edificações compõem o Eixo Central e são palco constante de manifestações, inclusive atividades artísticas e culturais. $\bigcirc$ Centro de Convivência, fechado por anos à espera de obras de requalificação, expressava na ociosidade dos ambientes os sinais de abandono e deterioração. Com os encontros ocorridos em 2019, os estudantes se mobilizaram para ocupar este edifício, resgatando sua função original de convívio estudantil. $\bigcirc$ Centro de Convivência possui um hall nivelado com a praça e encerrado com um painel de vidro nas duas extremidades, permitindo uma continuidade entre os usos externos e internos.

O CCE [Figura 5A] possui uma área de pilotis no seu térreo com relação direta para a Praça da Cidadania, expandindo-a. Embora este espaço tenha configuração linear como no Centro de Cultura e Eventos, a continuidade de nível de piso e a inexistência de elementos de fechamento favorecem a oportunidade de concentração e o acolhimento dos alunos. $\bigcirc$ edifício sempre teve um papel pedagógico integrador na grade curricular, sendo um dos poucos com essa natureza na universidade.

Áreas livres em outros setores do campus ganharam novo aspecto ao serem ocupadas como local de debate e troca de conhecimento a partir destes movimentos instaurados em 2019. Este anseio por espaços de convívio ficou ainda mais perceptível no episódio impresso na Figura 5B, em que os estudantes do Centro Tecnológico bloquearam o acesso veicular na área. A este movimento deram o nome de "vem pra praça", reconfigurando o espaço que cotidianamente é utilizado como estacionamento, apesar do grande potencial para a permanência de pessoas.
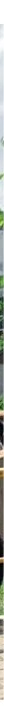


\section{À CIDADE}

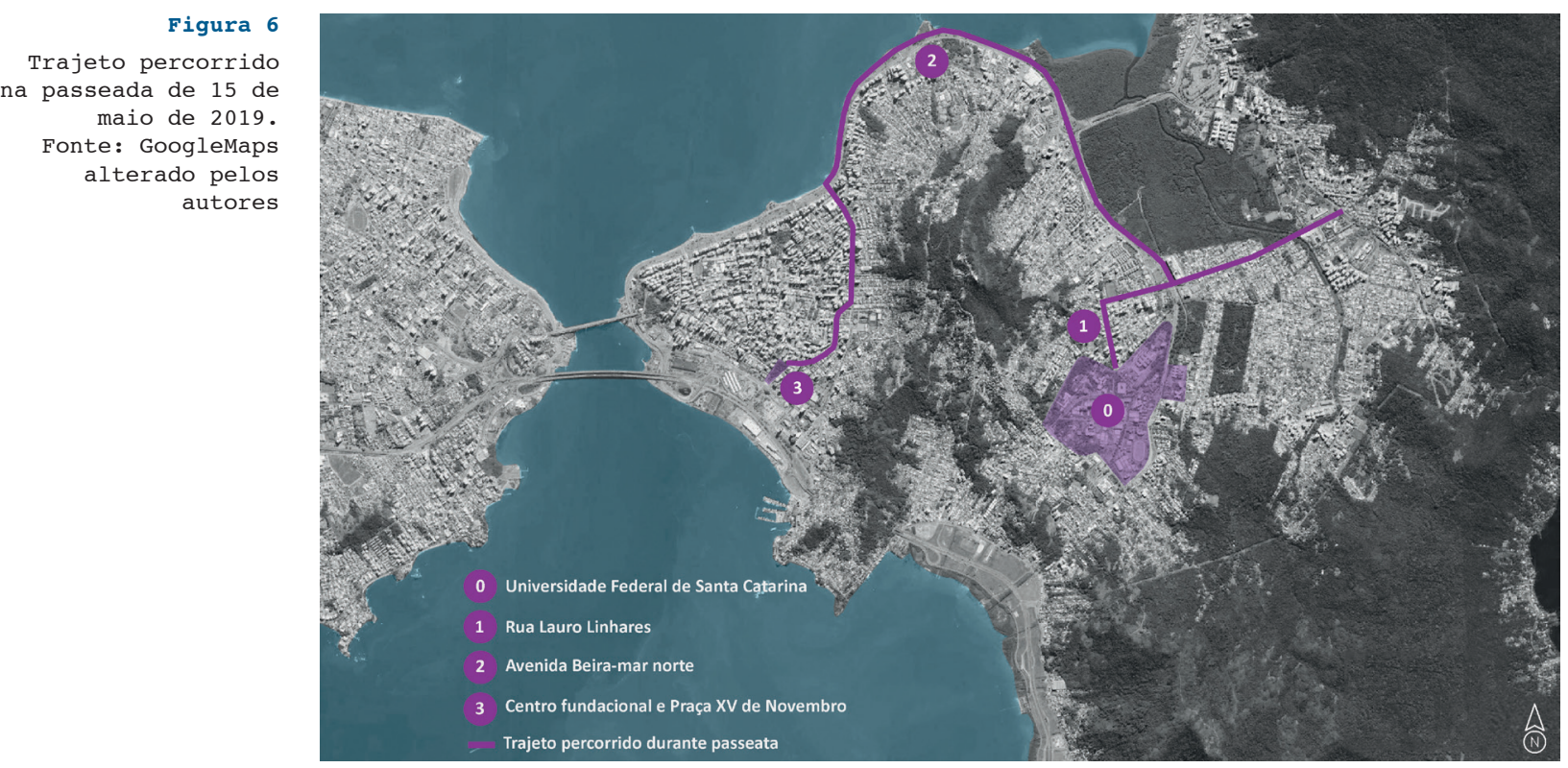

Como ponto de partida, importantes vias foram tomadas pela aglomeração. A Rua Lauro Linhares é, desde a fundação da UFSC, a principal via de acesso a pé ao campus. Com a expansão da universidade e a consequente densificação demográfica do entorno, a via foi assumindo um caráter predominantemente comercial e de serviços privados. Esta rua se limita hoje a calçadas de pedestres subdimensionadas em conflito com os carros que acessam as edificações e cuja arquitetura padrão restringe as possibilidades de encontro às áreas internas dos edifícios.

Além desta tipologia viária/comercial que se repete em outros trechos do percurso, deve-se destacar a Avenida Beira-mar [Figura 7C], 
local de fácil acesso e ligação entre o Centro de Florianópolis e o Campus da UFSC. Atrativo turístico reconhecido pela proximidade ao mar e infraestrutura viária, a via predominantemente residencial possui edifícios cujos térreos possuem relação limitada com os passeios que os tangenciam. Apesar desse distanciamento, é um dos principais espaços públicos que abriga as manifestações dos moradores da cidade que vêm ocorrendo desde junho de 2013.

Figura 7

Passeata de 15 de

maio de 2019.

Fonte:

A. Autores;

B. Dhiancarlo Picini;

C. Leonardo Thomé
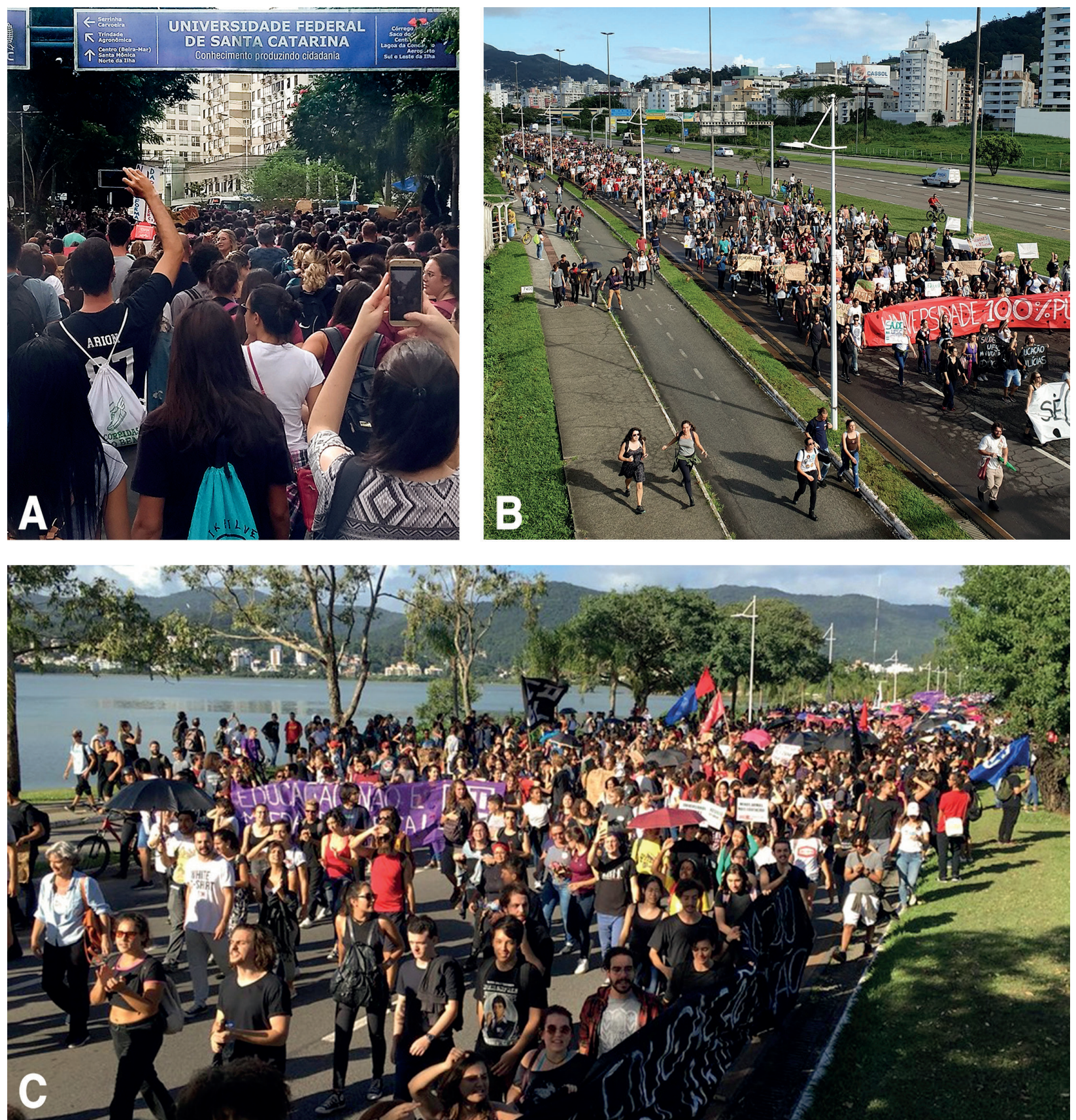


\section{DISCUSSÃO}

A passeata de maio de 2019, por fim, teve como destino a Praça $X V$ de Novembro, principal palco democrático localizado no Centro de Florianópolis. Ao longo dos 346 anos da cidade, o bairro é ainda um dos poucos locais que concentra as atividades comerciais mais tradicionais, de estabelecimentos voltados à rua com diálogo direto com espaços abertos, contrastando com o surgimento de centros comerciais onde a relação entre espaços públicos e privados é mais abrupta e controlada. A intensa ocupação e passagem de pessoas diariamente faz da praça e todo o complexo urbanístico que a contorna um marco cívico, abrigando notáveis eventos ao longo da história. É importante destacar que projetos para essa região (Gaspar et al., 2017) associam, através de iniciativas de marketing urbano, o rótulo de "Cidade Criativa" a Florianópolis com possíveis efeitos de ampliação de desigualdades e homogeneização do espaço público. (Gotham, 2005; Schöllmann, et al., 2000).

Nota-se que estes eventos, indiretamente, proporcionaram uma reinvenção do uso campus e da área conurbada em que está inserido, trazendo à tona experiências de encontro e debate adormecidas em diferentes períodos da história. Enquanto os dados de Wi-Fi demonstraram que a fragmentação desenhada no campus ainda existe, a análise das assembleias demonstrou seu potencial de oferecer à cidade seu caráter cívico.

Quanto à arquitetura edificada, verificou-se que as características programáticas que compuseram as manifestações de 2019 têm constância espacial e temporal. Elas dependem e se amparam em edifícios cujo programa é pré-definido. Não obstante a essa determinação, uma relação de interdependência e continuidade entre os limites das edificações ainda é constatada. Somam-se ainda a esses aspectos a dimensão dos edifícios e a sua implantação no campus.

Uma das mais substanciais obras que ilustram este cenário é a Reitoria, cujo acesso principal e hall do térreo formam uma continuidade de uso da Praça da Cidadania, palco de episódios democráticos históricos. $\bigcirc$ ambiente que configura o hall, por exemplo, possui dimensões propícias para a realização de grandes encontros, convidando à permanência pessoas que por vezes estão apenas de passagem. Contudo, o Centro de Cultura e Eventos não possui tipologia que potencialize a continuidade dos encontros que ocorrem na praça, limitando seu uso a eventos fechados.

Os eventos abertos, como encontros acadêmicos e apresentações artísticas, são mais frequentes no CCE, dada sua localização central e relação direta entre a praça e os pilotis. Há cerca de uma década, estes eventos passaram a ser controlados devido à pressão de parte da administração que se demonstrava incomodada com a aglomeração dos estudantes, solicitando constantemente o fechamento desta área do edifício visando coibir suas manifestações.

A retomada das atividades culturais na UFSC está conectada ao fato de o campus poder oferecer serviços e espaços mais cívicos do 
Figura 8

Proposta de inte-

gração do campus pe-

las áreas verdes.

Fonte: Elaboração

própria que comerciais. A universidade tem a possibilidade de ter essa postura, com serviços gratuitos demonstrando um espaço que a cidade ganha da universidade, de maneira que o campus possua mais diversidade e consiga encampar esse papel de congregação das pessoas. Durante as narrativas das assembleias, essa demanda ficou evidente ao se requerer novos espaços que promovam este exercício para além da Praça da Cidadania, principalmente conectados às áreas verdes, como simulado na Figura 8, integrando o campus à cidade através da requalificação dos córregos. Tendo como conectores os edifícios que abrigam serviços gratuitos oferecidos a comunidade e a praça como espaço de convergência, um novo trajeto para dentro do campus pode torná-lo um eixo de conexão atrativo para a livre atuação cívica de toda a cidade.

Para Lefebvre (1996), excluir grupos e indivíduos da cidade também é excluí-los da civilização, senão da própria sociedade. A apropriação do campus pelos moradores reforça esse caráter cívico e o papel que a universidade pode desempenhar em movimentos que promovam a diversidade e a redução das desigualdades. A iniciativa dos estudantes de difundir o conhecimento produzido, de dentro da universidade para os espaços da cidade vai nesse sentido. Do contexto político de 2019 e visando demonstrar à sociedade civil a importância da produção científica e torná-la aliada em defesa da educação pública, surgiu por parte dos estudantes o movimento "UFSC na Praça", onde estudantes de diversas áreas estruturaram exposições nas praças dos principais bairros, transformando aqueles espaços em verdadeiras salas de aula.

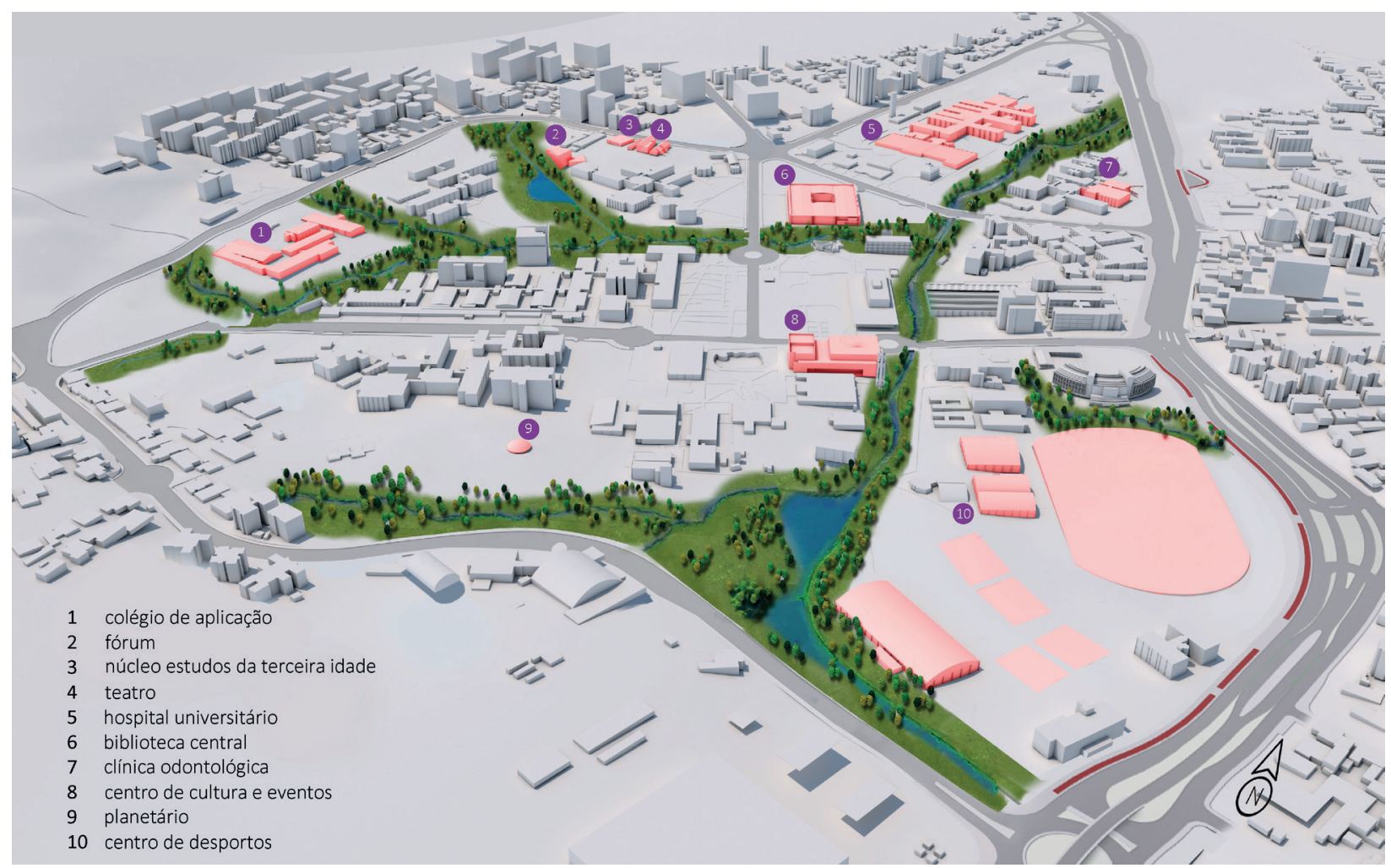


Deve-se ter em conta a mudança estrutural por que passam há mais de uma década as universidades públicas brasileiras. Desde a implementação dos programas de ações afirmativas no ano de 2008, a UFSC atende um número crescente de pessoas em situação econômica vulnerável, negros e indígenas, colaborando para um quadro demográfico menos segregado (Passos, 20 I5). A UFSC mudou e está, ainda que moderadamente, menos elitizada, mas a arquitetura dos seus espaços não tem acompanhado este potencial democrático do campus.

Projetar campi que promovam o caráter cívico e a construção de comunidades deve ser prioridade nos círculos vinculados à educação pública, mesmo com escassos recursos (Klinenberg, 20 I8). Essas questões latentes emergem de formas excepcionais, como comentado a respeito do estacionamento, onde a reconquista do espaço de uso privado promoveu sua reinvenção. Mas essa postura sempre esteve no cerne das universidades, como quando, abrindo seu território físico à comunidade, a UFSC amplia expressivamente a oferta de serviços vinculados à saúde; cultura e ao lazer.

Conflitos e contradições se reproduzem na cidade e no campus e são saudáveis em sociedades democráticas. Quando guiados, contudo, pelas dicotomias que transpassam os debates acerca do assunto, carregando a interpretação do campus como local alheio ao meio urbano que circunda, há prejuízo mútuo. Tais conflitos, por exemplo, podem ser ilustrados pelas diferentes visões sobre como o campus da UFSC deve ser gerido e opiniões contundentes sobre a decisão de abri-lo à comunidade ou fechá-lo com portões e cancelas aos finais de semana e à noite.

Partimos do entendimento de que o campus universitário é considerado em sua magnitude como uma infraestrutura social (Klinenberg, 2018) onde a tomada coletiva de decisões é reforçada por sua espacialidade que permite que essa postura alcance o domínio urbano, extrapolando os limites físicos e ideológicos da universidade. Deve-se ter em conta que a aparente "neutralidade" de infraestruturas, como tratado ao longo deste trabalho, carrega consigo uma mensagem muito mais profunda do que a facilitação de uma atividade em específico. Esses locais se fundem às questões de escala e complexidade das sociedades democráticas. Enquanto a busca de concepções metafóricas de espaço público é um esforço válido, e um empenho que tem feito muito para aprofundar as concepções sobre a democracia, Parkinson (2006) argumenta que é uma lástima que o papel físico dos espaços tenha sido ignorado nessa diligência. Ele sustenta que o espaço público importa muito para a democracia e que negligenciar esse fato tem consequências prejudiciais à saúde democrática da sociedade.

A postura de reinserção do campus deve ser ativa pois o único empecilho existente não está apenas na natureza quase antitética do termo campus em oposição à cidade, da mesma forma que algumas 
características são essenciais para que o campus não seja um espaço descolado da cidade. Sobretudo em edifícios construídos há mais de duas décadas ou com relevante papel integrador, existe um atributo de continuidade entre espaços externos e internos. Há lugar para indeterminação programática, para a apropriação informal e, principalmente, uma menor dependência de fachadas comerciais que se estendem a uma calçada apropriada quase que exclusivamente. A manutenção das características e arranjos espaciais que citamos é essencial para que o campus abrigue não somente a performance democrática de sua comunidade, mas para que seja cada vez mais capaz de acolher manifestações externas.

Quando abordamos manifestações que saem das dependências dos edifícios, seguem para as praças no entorno imediato e posteriormente deixam o campus em direção à cidade, reforçamos a asserção de que alguns tipos de espaços físicos são inseparáveis. Quando se trata de performance democrática, entre diversos outros aspectos que constituem as boas qualidades dos edifícios, o interior e o exterior são um continuum. A diversidade facilitada por um campus com edifícios e áreas livres convidativos e permeáveis para todos os cidadãos, como é o caso da UFSC, traz inestimáveis benefícios para uma universidade que reflete sobre o futuro da sociedade. $\bigcirc$ caminho que as manifestações tomaram como saída do campus em direção à cidade é um forte indicativo de como podemos fortalecer a entrada da cidade na universidade simbolicamente pelo que a manifestação representa e fisicamente por futuras intervenções que reforcem esse eixo. Da mesma forma, uma cidade cujos cidadãos contribuem para estas reflexões, através da participação em uma rede de amparo e colaboração mútuos na universidade, tem seu caráter cívico e democrático fortalecido. 


\section{REFERÊNCIAS BIBLIOGRÁFICAS}

ALMEIDA PINTO, G., \& BUFFA, E. (2009). Arquitetura e educação: câmpus universitários brasileiros. EdUFSCar.

BRASIL. (2014). A democratização e expansão da educação superior no país 2003-2014.

BRASIL. (2016). Proposta de Emenda à Constituição nº 55, de 2016.

BRENNER, N., MARCUSE, P., \& MAYER, M. (2009). Cities for people, not for profit. City, 13 (2-3), 176-184. https://doi.org/10.1080/13604810903020548

CASTELLS, M. (2015). Networks of outrage and hope: Social movements in the Internet age. New Jersey: John Wiley \& Sons.

CHAPMAN, M. P. (2006). American Places: In Search of the Twenty-First Century Campus. ACE/Praeger Series on Higher Education. Westport: Greenwood Press.

DOBER, R. P. (1992). Campus design. New York: Wiley.

GASPAR, J. V., MENEGAZZO, C., FIATES, J. E., TEIXEIRA, C. S., \& GOMES, L. S. R. (2017). A revitalização de espaços urbanos: O case do Centro Sapiens em Florianópolis. Revista Livre de Sustentabilidade e Empreendedorismo, 2(4), 183-205 GOTHAM, K. F. (2005). Theorizing urban spectacles. Festivals, tourism and the transformation of urban space. City, 9(2), 225-246. https://doi. org/10.1080/13604810500197020

HARVEY, D. (2003). The right to the city. International journal of urban and regional research, 27(4), 939-941. https://doi.org/10.1111/j.0309-1317.2003.00492.x

KLINENBERG, E. (2018). Palaces for the people: How social infrastructure can help fight inequality, polarization, and the decline of civic life. New York: Broadway Books.

LEFEBVRE, H., KOFMAN, E., \& LEBAS, E. (1996). Writings on cities (Vol. 63). Oxford: Blackwell.

MANGRICH C. P., PAVAN L. H., GOMES F., OLIVEIRA L., KOS J., MARTINA J. E. (2019). Campus regenerative design supported by university Wi-Fi connections. In International Journal of Architectural Computing (pp. 206-219). https://doi.org/10.1177/1478077119849682.

PARKINSON, J. (2006). Holistic democracy and physical public space. In British Journal of Political Science Conference (pp. 1-17). British Academy.

PARKINSON, J. (2012). Democracy and public space: The physical sites of democratic performance. Oxford: Oxford University Press.

PARKINSON, J. (2013). How is space public? Implications for spatial policy and democracy. Environment and Planning C: Government and Policy, 31(4), 682699. https://doi.org/10.1068\%2Fc11226r

PASSOS, J. C. D. (2015). Relações raciais, cultura acadêmica e tensionamentos após ações afirmativas. Educação em Revista, 31(2), 155-182. https://doi. org/10.1590/0102-4698134242

PEREIRA, F. T. B. (2017). Exporting progress: os norte-americanos e o planejamento do campus no Brasil. Doctoral Thesis, Instituto de Arquitetura e Urbanismo, University of São Paulo, São Carlos. doi:10.11606/T.102.2017.tde04092017-105123.

SCHÖLLMANN, A., PERKINS, H. C., \& MOORE, K. (2000). Intersecting global and local influences in urban place promotion: The case of Christchurch, New Zealand. Environment and Planning A, 32(1), 55-76. https://doi.org/10.1068\%2Fa31185.

SUNSTEIN, C. R. (2018). \# Republic: Divided democracy in the age of social media. Princeton University Press.

TEIXEIRA, L. E. F. (2009). Arquitetura e cidade: a modernidade (possível) em Florianópolis, Santa Catarina-1930-1960 (Doctoral dissertation, Universidade de São Paulo).

TEIXEIRA, L., YUNES, G., SOUZA, R., SANSÃO, M., \& GODOY, M. (2014). Um itinerário para a arquitetura moderna em Florianópolis. Cadernos NAUI, 3(4). 